articles reviewed above have been stimulated by the Plan and are an indicator of the high level of activity in the field.

Despite these developments, sufferers continue to struggle with the day-to-day realities of the disease. Support groups say that even more needs to be done, especially in education for families, their GPs and other health professionals, to prevent families turning to ACATs at a crisis. The Federal government plans a community education programme which should facilitate the implementation of the Plan. Other studies are underway to improve knowledge of how to meet the care needs of people with complex dementias and behaviour. They have also been stimulated by the Plan and are funded from a $\$ 12.4$ million psychogeriatric care and support initiative announced in the 1994/95 Federal budget.

\title{
NOTE
}

I The World Wide Web address is: 〈http://werple.mira.net.au/ dhs/ad.html〉.

School of Social Work, University of Melbourne

\section{Social Services Expenditure}

\section{Paul Plant}
A. C. Bebbington and A. Kelly. 1995. Expenditure planning in the personal social services: unit costs in the I 980 . Journal of Social Policy, $24(3), 3^{8} 5-41$ I.

Between $1978 / 79$ and $1988 / 89$ there was a 41 per cent real increase in net current expenditure on personal social services in England and Wales, equivalent to a growth rate of 3.5 per cent per annum. Concerns about whether this level of expenditure growth was sufficient has focused on the increased need for social services due to changes in: socio-economic conditions, e.g. the rise in the numbers of unemployed and homelessness; demography, e.g. the increase in the number of the very old; or the responsibility of services, e.g. due to the Children's Act and care in the community. Little work has examined the implications of rising costs on the ability of local authorities to provide services, which the authors of this paper attempt to rectify.

They start by showing how the trends in cost inflation during the rg70s continued into the I980s, to the extent that they more than swallowed up all the expenditure increase, leading to a io per cent reduction in the volume of services provided. Three factors that could 
have caused the increased costs are explored: the costs of labour; changes in the relationship between inputs and outputs; and changes in the needs of the clients served. Over all service provision, the real price of labour inputs rose during the 1980 , with the average cost per member of staff increasing by 22 per cent. Such an increase accounts for less than half of the overall 48 per cent increase in unit costs. With pay scales only keeping up with inflation, the increase resulted from the re-grading of many employee groups, and the introduction of certain bonuses to retain staff in areas of perceived shortage.

An increase in the number of staff employed, combined with the fall in volume of services, points to an increased staff/client ratio over the period. Without proper studies looking at the effect of this change on client outcomes, however, Bebbington and Kelly point out that it is difficult to know whether these were the result of intentional increases in service quality or of unintentional reductions in efficiency. This was looked at more closely with respect to individual services, as were potential changes in the characteristics of the client groups served. Changes in the level of dependency of elderly clients could not account for the increased cost of residential provision, whereas an important marker of the efficiency with which such care is provided, the average occupancy level within homes, fell over the decade from 95 to 90 per cent.

With respect to home care, average productivity did not increase over the period and the nature of the workload of home care assistants changed little, even though much discussion took place about the role of these services in maintaining in their own home those people who would otherwise have been cared for in a residential setting. The authors argue that it can be concluded that job re-grading was the major contributing factor to cost inflation. Changes in policy and practice over time make trend analyses difficult in the case of residential care for people with learning disabilities. Bebbington and Kelly quote work which has demonstrated that, after controlling for several factors that affect costs, local authority facilities cost 35 per cent more per person day than equivalent facilities in the private sector. This finding does not in itself show however whether efficiency levels within the local authority sector decreased during the period.

The authors argue that with respect to services for children in care, unit costs might have been expected to decline, due to decreases in the proportion of young offenders and the average age of children in care. As costs rose this must point to decreased efficiency. The number of support staff (management, administration, R\&D, training and field social work) remained constant at 22 per cent of all staff. The number 
of managers expanded rapidly, however, which contributed to a i 7 per cent increase in the cost of supporting each pound of expenditure on direct services. If there was an overall reduction in efficiency, it did not affect all local authorities uniformly. The unit cost differential between London and the rest of the country widened. Inner London's costs rose from $3^{2}$ to $5^{6}$ per cent above the outside-London average. Those authorities that had the greatest increase in unit costs had the least increase (or greatest decrease) in service volumes and vice versa. The correlation between unit cost increase and volume decrease was -0.4 . The pattern of results suggest that, in response to 'the fiscal pressure exerted on local authorities during the 1980 , some responded by keeping unit costs down but maintaining services to the maximum number of clients, while others allowed unit costs to rise but concentrated resources on a restricted number of clients'. There is little evidence that those authorities in which the volume/cost ratio declined most have been developing more intensive, targeted and higher quality services.

The authors conclude their analyses by examining whether the various pressures placed on spending over the period (reduction in the size of the government grant, 'rate capping', and decrease in the local tax base) had differential impacts on unit cost and volume changes. Grant control did not appear to target the authorities regarded as most inefficient. Those authorities that came under most fiscal pressure from a declining grant and rateable values responded by keeping costs down and maintaining service volumes. By contrast, up to 1989 , rate-capping had no obvious effect on controlling the expansion in unit costs, though it contributed to the reduction in services. The authors conclude that those authorities which have a high level of unit costs, not those with a high volume of provision, are 'badly' treated by standard spending assessments in relation to their actual spending. They also go on to argue that the introduction of quasi-markets in social care, as a result of the Community Care Act, may increase the incentives for managers to monitor and control costs and thereby increase the efficiency with which social services are provided.

\section{COMMENT}

Bebbington and Kelly's paper represents an interesting review of the overall trend in United Kingdom social service provision and unit costs during the ig8os. It opens up questions about the impact that cost efficiency has on the volume of services delivered. Moreover, by looking at variations between local authorities in the relative efficiency with 
which they delivered services, and how they appear to have responded to different fiscal pressures, important policy issues are raised in relation to the equity of service provision and how central government action can best influence spending patterns. The research is weakened, however, by the lack of information on how client needs have really changed over the period. Only indicators of need at the national level are adduced as evidence that changes in this respect cannot account for the increase in unit costs. The analysis should have linked change in service volumes, unit costs and need within each local authority. Important inter-authority variations in the relationship between these factors may have been masked using national summary statistics, e.g. the gap in income between the top and bottom of the distribution has widened, which is likely to be reflected in geographical inequalities. Also, as stated by the authors, the important changes in staff/client ratios need to be studied in relation to client outcomes, before statements relating to cost efficiency can be made with confidence.

Institute of Public Health, Tunbridge Wells, Kent 